\title{
Determination of Elastic Wave Velocities in Rocks by Means of Ultrasonic Impulse Transmission.
}

\author{
By \\ Akira KuBotera. \\ Geophysical Institute, Faculty of Science, Kyoto University, Kyoto.
}

\begin{abstract}
Velocities of longitudinal and transversal elastic waves in rock specimens have been determined from the transmission times of ultrasonic impulse ( $50 \mathrm{KC}-300 \mathrm{KC}$ ) through them at ordinary temperatures and pressures. Porsson's ratios have also been calculated from the velocities of the two kinds of elastic waves.

18 specimens of granite and 34 of marble, all collected from various localities of Japan, were examined. In addition, 12 apecimens of marble from Italy and various other kinds of rock, such as andesite, sandstone, tuff, etc. were also examined. The experimental results are summarised as follows:
\end{abstract}

\begin{tabular}{l|c|c|c}
\hline & $\begin{array}{c}\text { longitudinal } \\
\text { wave }(\mathrm{km} / \mathrm{sec} .)\end{array}$ & $\begin{array}{c}\text { transversal } \\
\text { wave (km/sec.) }\end{array}$ & $\begin{array}{c}\text { Porsson's } \\
\text { ratio }\end{array}$ \\
\hline Granite & $4.09-5.89$ & $2.51-3.55$ & $0.19-0.28$ \\
Marble & $3.75-6.94$ & $2.02-3.86$ & $0.18-0.35$ \\
\hline
\end{tabular}

Within the frequency range of our experiments, dispersion phenomena have been found in none of the rock specimens examined.

\section{$\S 1$. Introduction}

The elastic constants of rocks for low and audio-frequencies have been measured by a number of workers. In experimental loboratories, the constants can be determined from the resonance frequency of a rod of rock specimen which is subjected to standing elastic vibrations (K. IrDA: 1939). In fields, on the other hand, the constants can most directly be determined from the time of transmission of artificial or natural seismic waves. If one wishes to use this direct method in laboratories, an inconveniently long specimen of rock will be needed, because the specimen must be at least several times as long as the wave-length of the elastic wave used. This difficulty will disappear if ultrasonic frequency is used instead of audiofrequency. In the present paper, the writer is going to describe the results of his loboratory determinations of elastic constants of rocks from the time of transmission of ultra- sonic waves $(50 \mathrm{KC}-300 \mathrm{KC})$ in rock specimens. The dimensions of the specimens are $20 \mathrm{~cm} \times$ $17 \mathrm{~cm} \times 6 \mathrm{~cm}$ in case of granite and $12 \mathrm{~cm} \times 9$ $\mathrm{cm} \times(2 \sim 1) \mathrm{cm}$ in case of marble.

\section{§2. Apparatus and Experimental Method}

Fig. 1 shows the general view of the apparatus used and Fig. 2 is its schematic diagram. The apparatus consists of a pulse generator, pulse amplifier, sweep circuit, time mark circuit and cathod-ray oscillograph.

$\mathrm{BaTiO}_{3}$ crystals were used to generate and receive ultrasonic waves of $50 \mathrm{KC}$, while quartz crystals were used for $150 \mathrm{KC}$ and 300 $\mathrm{KC}$. For the latter case, X-cut crystals were used for longitudinal waves, while Y-cut crystals were used for transversal waves. D. S. Hughes and J. H. Cross (1951) used X-cut crystals for both kinds of waves, but according to the writer's experiences, Y-cut crystals are more adapted for transversal waves.

The pulse generator (including power am- 
plifier) which excites the crystals has been so designed that the pulse is sent into the specimen a short time after the sweep circuit bigins to operate. Sweep signals are fed to the horizontal plate circuit of the cathod-ray oscillograph while the imput impulse to the rock specimen and the output impulse from it are both fed to the vertical plate circuit of

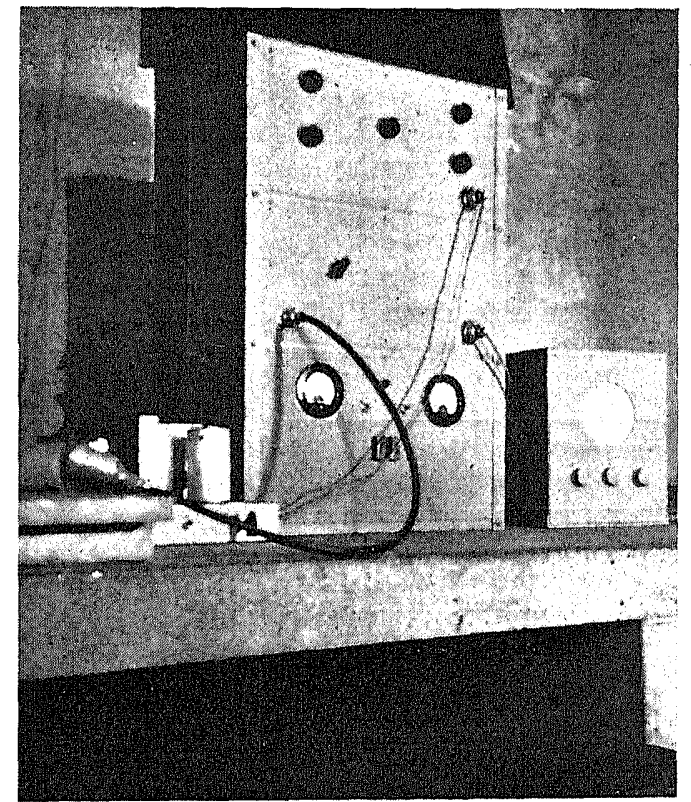

Fig. 1. General view of the experimental apparatus.

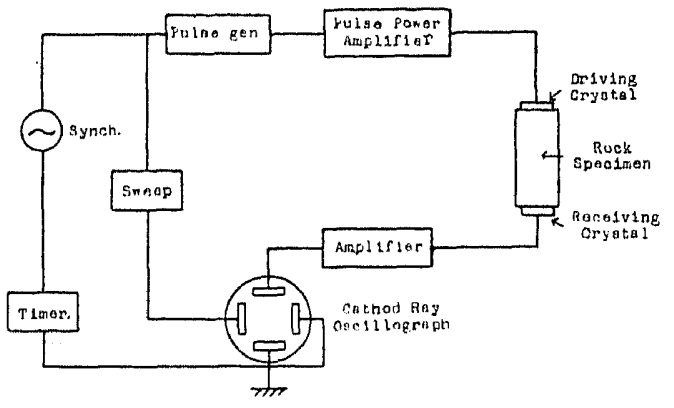

Fig. 2. Schematic diagram of the experimental apparatus.

the oscillograph together with time marks. The time marks are given at every $3 \pm 0.06$ microseconds. The apparatus was designed by Assistant Professor F. Kondo of the Department of Electrical Engineering, Kyoto
University, and was constructed by his assistant, Mr. T. Yamada. .

\section{§3. Rock Specimens}

The rock specimens examined are as follows:

$\begin{array}{lrl}\text { Granite } & 18 & \text { Japan } \\ \text { Marble } & 33 & \text { Japan } \\ \text { Marble } & 12 & \text { Italy } \\ \text { Marble } & 1 & \text { Korea, }\end{array}$

all collected by Mr. S. NAGaoka. These were placed at the writer's disposal by the kindness of Professor S. Matsushrma. The localities from which they were collected are listed in Tables I and II. Each of the rock specimens has its own characteristic appearance and has the proper name according to its place of occurrence as also listed in the tables. The properties of these specimens of granite and marble are believed to be such that they well represent those of the corresponding rocks which occur in their respective places. Unfortunately, however, chemical and mineralogical compositions of the specimens have not yet been determined.

\section{§4. Results}

The cathod-ray oscillograms due to longitudinal and transversal waves in rock specimens were taken photographically. Fig. 3 is one of the records obtained for a granite specimen. On the first record are shown the incident and received wave pulses due to the $\mathrm{X}$-cut quartz crystal oscillations, while the third those due to the Y-cut crystal oscillations. The second and fourth records are time marks corresponding to the records above them. As is clear from the records, when the X-cut crystal is used, only one phase can be seen in the wave trains received. This phase corresponds to the longitudinal wave. In contrast to this, when the Y-cut crystal is used, the wave trains received show two sharply distinguishable phases, the first smaller one corresponding to the longitudinal wave and the latter larger one to the transversal wave. It is likely that in case of the Y-cut, while the main oscillations of the 

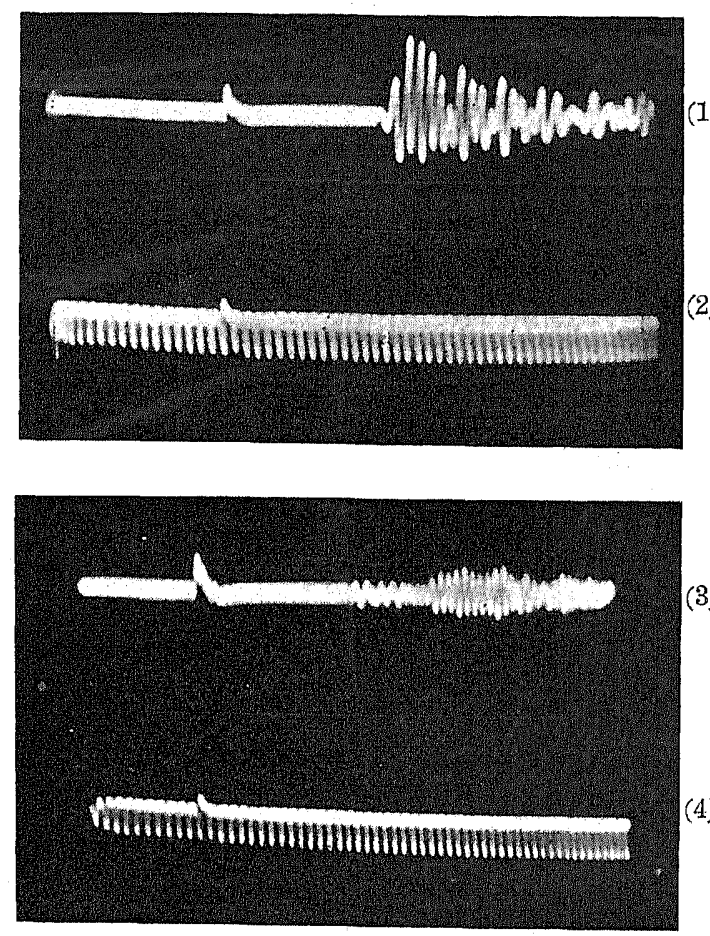

(1) Longitudinal wave of X-cut crystal.

(2) Time Mark.

(3) Longitudinal and transversal waves of Y-cut crystal.

(4) Time Mark.

Fig. 3. An example of records obtained for a granite specimen.

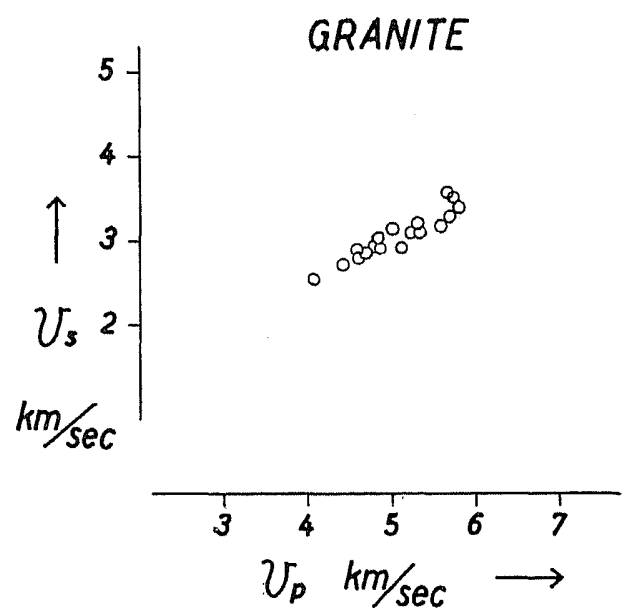

Fig. 4. Longitudinal and transversal wave velocities in granite specimens.

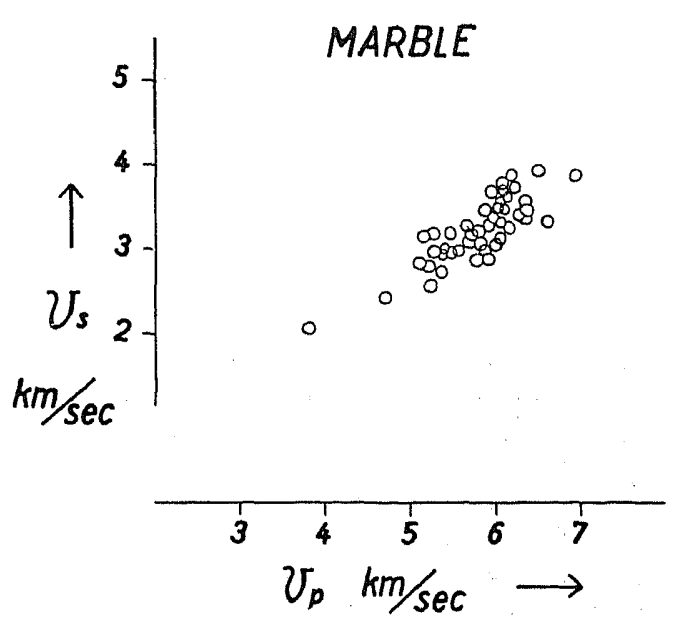

Fig. 5. Longitudinal and transversal wave velocities in marble specimens.

crystal are in $\mathrm{X}$-direction and produce the transversal wave, those in Y-direction due to the thickness oscillation produce the longitudinal wave.

The velocities of longitudinal and transversal waves obtained for various specimens are listed in Tables I and II for granite and marble specimens respectively. Figs. 4 and 5 have been obtained by taking the transversal wave velocity $v_{s}$ in ordinate and the longitudinal wave velocity $v_{p}$ in abscissa. The points in these figures are seen to lie approximately on a straight line within a certain range of velocity values. The velocities of elastic waves in granite and marble range as follows:

\begin{tabular}{c|c|c}
\hline & $v_{p}(\mathrm{~km} / \mathrm{sec})$ & $v_{s}(\mathrm{~km} / \mathrm{sec})$. \\
\hline Granite & $4.09-5.89$ & $2.51-3.55$ \\
Marble & $3.75-6.94$ & $2.02-3.86$ \\
\hline
\end{tabular}

Porsson's ratios as well as densities of the rock specimens are also given in Tables I and II. The range and the average values of Porsson's ratio are as follows:

\begin{tabular}{c|c|c}
\hline & range & average \\
\hline Granite & $0.19-0.28$ & 0.23 \\
Marble & $0.18-0.35$ & 0.27 \\
\hline
\end{tabular}


Table I. Locality, Proper Name, Longitudinal and Transversal Wave Velocities, Porsson's Ratio and Density of Granite.

\begin{tabular}{|c|c|c|c|c|c|c|}
\hline No. & Locality & $\begin{array}{c}\text { Proper Name } \\
\text { (Japanese) }\end{array}$ & $V_{p} \mathrm{~km} / \mathrm{sec}$ & $V_{s} \mathrm{~km} / \mathrm{sec}$ & $\begin{array}{l}\text { Poisson's } \\
\text { ratio }\end{array}$ & $\begin{array}{l}\text { Density } \\
\mathrm{gx} / \mathrm{cm}^{3}\end{array}$ \\
\hline 1 & Hyogo-Pref. & Alkao-ishi & 5.75 & 3.27 & .26 & 2.86 \\
\hline 2 & $" \prime$ & Hon-mikage (I) & 5.77 & 3.50 & .21 & 2.77 \\
\hline 3 & $" \prime$ & $"$ (II) & 5.38 & 3.16 & .28 & 2.79 \\
\hline 4 & Ôsaka-Pref. & Kitazima-ishi & 5.89 & 3.37 & .26 & 2.76 \\
\hline 5 & $"$ & $"$ & 5.63 & 3.16 & .27 & 2.77 \\
\hline 6 & Aichi-Pref. & Kuro-sansyu-mikage & 4.91 & 2.89 & .24 & 2.65 \\
\hline 7 & Ehime-Pref. & Oshima-ishi & 4.45 & 2.70 & .21 & 2.78 \\
\hline 8 & Kagawa-Pref. & Yoshima-ishi & 4.86 & 3.00 & .19 & 2.77 \\
\hline 9 & " & Agi-ishi & 4.56 & 2.78 & .21 & 2.71 \\
\hline 10 & $"$ & Shokai & 5.40 & 3.05 & .27 & 2.70 \\
\hline 11 & Okayama-Pref. & Kitaki & 4.83 & 2.96 & .20 & 2.68 \\
\hline 12 & $"$ & Sabi-ishi & 5.02 & 3.10 & .19 & 2.62 \\
\hline 13 & $" \prime$ & " & 5.30 & 3.03 & .26 & 2.94 \\
\hline 14 & " & Inushima-ishi & 5.18 & 2.88 & .28 & 2.87 \\
\hline 15 & $"$ & Aoki-ishi & 4.09 & 2.51 & .20 & 2.77 \\
\hline 16 & $" n$ & Kitaki-ishi & 5.71 & 3.55 & .19 & 2.70 \\
\hline 17 & " & Mansei-ishi & 4.77 & 2.81 & .24 & 2.70 \\
\hline 18 & " & Muneage-ishi & 4.62 & 2.85 & .19 & 2.77 \\
\hline
\end{tabular}
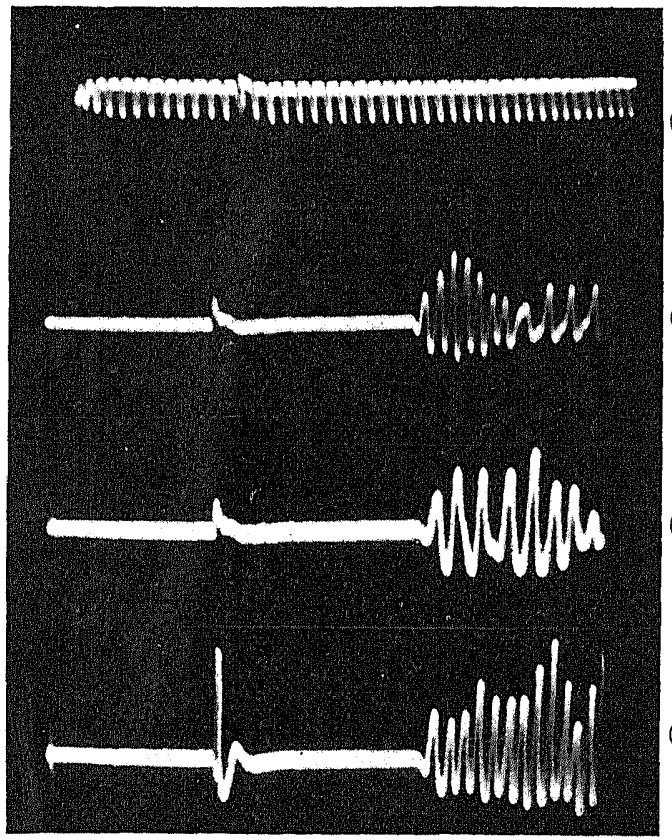

Fig. 6. Longitudinal waves in a sandstone specimen excited by different frequencies.
(1) Time mark. (8 microseconds.)

(2) $300 \mathrm{kc} / \mathrm{sec}$. X-cut crystal.

(B) $150 \mathrm{kc} / \mathrm{sec}$. X-cut crystal.

(4) $50 \mathrm{kc} / \mathrm{sec} \cdot \mathrm{BaTiO}_{3}$.

The average values of Porsson's ratio as determined by our experiments agree with Brrch's value (1938). The averages of the (2) ratios of the longitudinal and transversal wave velocities are as follows:

\begin{tabular}{l|l}
\hline & ratio \\
Granite & 1.69 \\
Marble & 1.78 \\
\hline
\end{tabular}

Finally, no tendency has been found that the velocity of elastic waves depends on the ultrasonic frequency within our frequency (4) range $(50 \mathrm{KC}-300 \mathrm{KC})$ and also within the accuracy of our experiments. One of the experimental results which indicates this conclusion is shown in Fig. 6. This record was taken with a sandstone specimen. Although 
Table II. Locality, Proper Name, Longitudinal and Transversal Wave Velocities, Porsson's Ratio and Density of Marble.

\begin{tabular}{|c|c|c|c|c|c|c|c|}
\hline No. & Locality & & $\begin{array}{l}\text { Proper Name } \\
\text { (Japanese) }\end{array}$ & $\begin{array}{c}V_{p} \\
\mathrm{~km} / \mathrm{sec} .\end{array}$ & $\begin{array}{c}V_{s} \\
\mathrm{~km} / \mathrm{sec} .\end{array}$ & $\begin{array}{c}\text { PoIsson's } \\
\text { ratio }\end{array}$ & $\begin{array}{l}\text { Density } \\
\mathrm{gr} / \mathrm{cm}^{3}\end{array}$ \\
\hline 1 & Yamaguchi-Pref. & Akiyoshi & Shiro & 5.62 & 3.26 & .25 & 2.66 \\
\hline 2 & $"$ & $"$ & Hakuchuzitu & 5.97 & 3.32 & .28 & 2.73 \\
\hline 3 & $" \prime$ & $" \prime$ & Midoriiriishi & 5.34 & 2.96 & .28 & 2.80 \\
\hline 4 & $"$ & $"$ & Shirakumo & 6.08 & 3.73 & .20 & 2.98 \\
\hline 5 & $" \prime$ & $"$ & Usugumo & 5.48 & 2.92 & .80 & 2.76 \\
\hline 6 & $"$ & $"$ & Hakuyo & 6.14 & 3.22 & .31 & 2.76 \\
\hline 7 & $" \prime$ & $" \prime$ & " & 5.09 & 2.80 & .28 & 2.73 \\
\hline 8 & $"$ & $"$ & Oka sarasa & 5.89 & 2.96 & .38 & 2.73 \\
\hline 9 & $"$ & $" \prime$ & Kinmon & 5.85 & 3.46 & .28 & 2.79 \\
\hline 10 & $"$ & $"$ & Kinteki & 5.89 & 2.83 & .35 & 2.74 \\
\hline 11 & " & $"$ & " & 6.02 & 3.54 & .24 & 2.72 \\
\hline 12 & $"$ & $"$ & Oka & 3.75 & 2.02 & .29 & 2.68 \\
\hline 13 & $" \prime$ & $"$ & " & 5.11 & 3.12 & .21 & 2.66 \\
\hline 14 & $"$ & Omine & Hakuyo & 5.25 & 3.13 & .24 & 2.83 \\
\hline 15 & $"$ & " & Shisuiseki & 6.15 & 3.84 & .18 & 2.66 \\
\hline 16 & $"$ & $" \prime$ & Uzura & 6.05 & 3.48 & .26 & 2.72 \\
\hline 17 & $"$ & Ota & Sarasa & 6.37 & 3.81 & .31 & 2.70 \\
\hline 18 & $" \prime$ & $"$ & Olkibuse & 5.92 & 3.64 & .19 & 2.80 \\
\hline 19 & Tokushima-Pref. & Tokushima & Kamo & 6.48 & 3.92 & .21 & 2.76 \\
\hline 20 & . I & " & Kinkamo & 6.34 & 3.43 & .29 & 2.76 \\
\hline 21 & $" \prime$ & $"$ & Aka-kamo & 5.98 & 3.04 & .33 & 2.76 \\
\hline 22 & $"$ & Akaishi & Sato-shima & 5.80 & 3.07 & .31 & 2.72 \\
\hline 23 & $" \prime$ & $"$ & Kinkaseki & 6.10 & 3.70 & .27 & 2.79 \\
\hline 24 & Kochi-Pref. Koc & & Ao-keiryu & 5.41 & 3.15 & .24 & 2.72 \\
\hline 25 & " " & & Keiryu & 5.67 & 2.10 & .29 & 2.82 \\
\hline 26 & Gifu-Pref. Akas & & Ki-sarasa & 6.94 & 3.86 & .28 & 2.74 \\
\hline 27 & " " & & Aka-sarasa & 6.16 & 3.76 & .21 & 2.70 \\
\hline 28 & " & & " & 6.10 & 3.70 & .21 & 2.69 \\
\hline 29 & " & & Kuro-sarasa & 6.01 & 3.50 & .24 & 2.62 \\
\hline 30 & " & & Kuro & 6.19 & 3.75 & .21 & 2.70 \\
\hline 31 & Ibaragi-Pref. M & yumiyama & Shimanezumi & 6.23 & 3.38 & .29 & 2.72 \\
\hline 32 & Okayama-Pref. I & Jaruha & Ailko & 5.72 & 3.18 & .28 & 2.72 \\
\hline 33 & Wakayama-Pref. & Yuasa & Kamo & 6.02 & 3.10 & .32 & 2.73 \\
\hline 34 & Yamanashi-Pref. & & Shihanseki & 5.14 & 2.72 & .30 & 2.80 \\
\hline 35 & Ryukyu Islands & & "I & 5.38 & 3.00 & .28 & 2.39 \\
\hline 36 & Korea, Heizyo & & Akagasumi & 6.00 & 3.30 & .28 & 2.70 \\
\hline 37 & Italy & & & 6.33 & 3.51 & .26 & 2.66 \\
\hline 38 & $"$ & & & 5.90 & 3.28 & .28 & 2.58 \\
\hline 39 & $"$ & & & 5.70 & 3.20 & .27 & 2.75 \\
\hline 40 & " & & & 5.58 & 2.99 & .29 & 2.59 \\
\hline 41 & $" \prime$ & & & 5.25 & 2.92 & .28 & 2.62 \\
\hline 42 & $"$ & & & 4.68 & 2.43 & .28 & 2.88 \\
\hline 43 & " & & & 5.31 & 2.75 & .82 & 2.82 \\
\hline 44 & " & & & 6.62 & 3.31 & .83 & 2.6 .4 \\
\hline 45 & $"$ & & & 5.20 & 2.53 & .35 & 2.75 \\
\hline 46 & $"$ & & & 5.74 & 2.84 & .34 & $2.7: 2$ \\
\hline
\end{tabular}


three different frequencies were used as indicated in the figure, no difference is seen in the time between the imput and arrival of waves.

So far, the results for granite and marble have been described. We have made similar experiments for about 150 specimens of other kinds of rock. The results of these experiments will be reported in the near future.

\section{Acknowledgements}

The writer wishes to express his gratitudes to Professor K. Sassa, Professor E. Nishimura, both of the Geophysical Institute of Kyoto University, and Professor S. Matsushima of the Geological Institute, and Assistant Professor F. Kondo of the Department of Electrical Engineering of the same university, for their many valuable discussions. Many thankes are also due to Mr. K. Nakazawa,
Mr. T. Yamada and Mr. T. Shinohara for their assistance in the experiments. The present study has been supported by the Grant in Aid for the Miscellaneous Scientific Researches of the Department of Education.

\section{References}

BIrCh, F., and BANCroft, D.:

1936 "The Effect of Pressure on the Rigidity of Rocks." Journ. Geol.. 46, 59-141.

HuGHes, D.S., and Cross, J.H.:

1951 "Elastic Wave Velocities at High Pressures and Temperatures." Geophysics, 16, $577-593$.

IIDA, K.:

1938 "Determining YounG's Modulus and the Solid Viscosity Coefficients of Rocks by the Vibration Method." Bull. Earthq. Res. Inst., 17, 79-92. 